\title{
Global Emergency Medicine: A Review of the Literature From 2013
}

Torben K. Becker, MD, Gabrielle A. Jacquet, MD, MPH, Regan Marsh, MD, MPH, Erika D. Schroeder, MD, MPH, Mark Foran, MD, MPH, Susan Bartels, MD, MPH, Herbert C. Duber, MD, MPH, Hannah Cockrell, and Adam C. Levine, MD, MPH, on behalf of the Global Emergency Medicine Literature Review (GEMLR) Group*

\section{Abstract \\ Objectives: The Global Emergency Medicine Literature Review (GEMLR) conducts an annual search of peer-reviewed and grey literature relevant to global emergency medicine (EM) to identify, review, and disseminate the most important new research in this field to a worldwide audience of academics and clinical practitioners.}

Methods: This year 8,768 articles written in six languages were identified by our search. These articles were distributed among 22 reviewers for initial screening based on their relevance to the field of global EM. An additional two reviewers searched the grey literature. A total of 434 articles were deemed appropriate by at least one reviewer and approved by an editor for formal scoring of overall quality and importance.

Results: Of the 434 articles that met our predetermined inclusion criteria, $65 \%$ were categorized as emergency care in resource-limited settings, 18\% as EM development, and 17\% as disaster and humanitarian response. A total of 24 articles received scores of 18 or higher and were selected for formal summary and critique. Interrater reliability for two reviewers using our scoring system was good, with an intraclass correlation coefficient of 0.63 (95\% confidence interval $=0.55$ to 0.69$)$. Infectious diseases, trauma, and the diagnosis and treatment of diseases common in resource-limited settings represented the majority of articles selected for final review.

Conclusions: In 2013, there were more emergency care in resource-limited settings articles, while the number of disaster and humanitarian response articles decreased, when compared to the 2012 review. However, the distribution of articles selected for full review did not change significantly. As in prior years, the majority of articles focused on infectious diseases, as well as trauma and injury prevention.

ACADEMIC EMERGENCY MEDICINE 2014;21:810-817 (c) 2014 by the Society for Academic Emergency Medicine

$\mathrm{T}$ he Global Emergency Medicine Literature Review (GEMLR) strives to ensure that emergency practitioners have access to the most current and important research conducted on relevant topics around the world. GEMLR began 9 years ago in an attempt to identify and consolidate the best global emergency medicine (EM) literature into a format that was easy for both academics and practitioners to access and compre-

From the Department of Emergency Medicine, University of Michigan (TKB), Ann Arbor, MI; the Department of Emergency Medicine, Boston University School of Medicine (GAJ), Boston, MA; the Boston University Center for Global Health and Development (GAJ), Boston, MA; the Department of Emergency Medicine, Brigham and Women's Hospital (RM), Boston, MA; Partners In Health (RM), Boston, MA; the Department of Emergency Medicine, Providence Regional Medical Center (EDS), Everett, WA; the Department of Emergency Medicine, New York University (MF), New York, NY; the Harvard Humanitarian Initiative (MF, SB, ACL), Cambridge, MA; the Department of Emergency Medicine, Beth Israel Deaconess Medical Center (SB), Boston, MA; the FXB Center for Health and Human Rights (SB), Boston, MA; the Division of Emergency Medicine, University of Washington (HCD), Seattle, WA; and the Department of Emergency Medicine, Rhode Island Hospital (HC, ACL), Providence, RI.

*Global Emergency Medicine Literature Review (GEMLR) Group members are listed in Appendix A.

Received April 11, 2014; accepted April 14, 2014.

The authors have no relevant financial information or potential conflicts of interest to disclose.

Supervising Editor: David C. Cone, MD.

Address for correspondence and reprints: Torben K. Becker, MD; e-mail: tbeckermd@gmail.com. 
hend. $^{1-8}$ This year, our panel of seasoned reviewers includes physicians from Canada, China, Ghana, Lebanon, Kenya, Sudan, the United Kingdom, and the United States.

This is also the fourth year that grey literature was included in our search strategy. Grey literature has been defined as any material produced by an organization whose primary function is not publication. ${ }^{9}$ Our goal in performing a grey literature search is to identify new global EM research conducted by government agencies, local or international nongovernment organizations, or other entities that may not have been published in peer-reviewed journals.

The primary goals of the review are to illustrate best practices; stimulate research; and promote further professionalization in the field of global EM through the identification of important new publications that focus on emergency care in the global context, including care provision in limited-resource settings, disaster and humanitarian response, and EM development. At the same time, it is important to note that GEMLR is not a formal systematic review or meta-analysis, as it does not aim to synthesize the published literature on a specific topic or research question. Instead, its goal is to identify the highest quality and most relevant global EM research from around the globe and synthesize them into a single, easy-to-use reference.

\section{METHODS}

Each year, the GEMLR editorial board revises a procedure manual that outlines in detail the methodology for its search, screening, scoring, and reviewing processes. ${ }^{10}$ Because the GEMLR is a review project, no prior ethical or institutional review board approval was sought for this article. There were nine editors, four advisors, one Academic Emergency Medicine representative, and 22 reviewers. As reviewers and editors were not blinded to the identities of the authors of the articles included in the review or their affiliations, both reviewers and editors were recused from scoring or reviewing any articles in which they may have been directly or indirectly involved.

The initial search was conducted in two blocks: the first from January 1 to August 31, 2013, and the second from September 1 to December 31, 2013. PubMed was used to search Medline for original research or review articles that contained at least one "global" search term and one "emergency medicine" search term (Table 1). Seven journals that publish significant numbers of global EM articles from prior GEMLR reviews were "hand searched," where all articles for that calendar year were included in the review. This year, the following journals were included in the hand search: Academic Emergency Medicine, African Journal of Emergency Medicine (new in 2013), Annals of Emergency Medicine, Bulletin of the World Health Organization, Emergency Medicine Journal, Prehospital and Disaster Medicine, and The Lancet. Based on the linguistic capacity of our reviewers and editors, our search this year was limited to articles published in Arabic, English, Chinese, French, German, Hindi, Italian, and Spanish. All studies were limited to human subjects only; news articles and letters were

Table 1
Search Terms
\begin{tabular}{|ll|}
\hline Emergency Medicine & \multicolumn{1}{c|}{ Global } \\
\hline Emergency medicine & World health \\
Refugees & Developing countries \\
Emergency treatment & International \\
Relief work & Global \\
Rescue work & Tropical medicine \\
Acute disease & Third world \\
Humanitarian & Middle-income countries \\
Critical illness & Low-income countries \\
War & Resource-limited settings \\
Prehospital & \\
Conflict & \\
Triage & \\
Disasters & \\
Multiple trauma & \\
Injuries & \\
Internally displaced persons & \\
Emergencies & \\
Emergency medical services & \\
Resuscitation & \\
Critical care & \\
Sepsis & \\
Shock & \\
\hline
\end{tabular}

excluded. Articles that had been e-published ahead of print in 2012 and had thus been included in the 2012 review were also excluded. The total number of articles produced by our PubMed search for 2013 was 5,294: 5,155 English, 44 French, 40 German, six Italian, 28 Spanish, and 21 Chinese. The total number of articles produced by our hand search for 2013 was 3,474. The 8,768 articles produced by these two searches were divided among the 22 reviewers for initial screening based on their relevance to the field of global EM. A total of 430 articles were deemed appropriate for formal scoring of their overall quality and importance by at least one reviewer based on GEMLR's screening criteria, approved by his or her editor.

For the grey literature search, we used a preidentified list of academic, government, and nongovernmental organizations known to be conducting global health research or investigations as part of their work (Table 2). Two reviewers were assigned to search the websites of these organizations for needs assessments, program monitoring, evaluation reports, topic reviews, white papers, conference proceedings, and other types of articles that met the predefined screening criteria for relevance to the field of global EM. Through our grey literature search process, we found four additional global EM research articles that met the inclusion criteria; these were combined with those identified by the Medline and hand search processes to create a final database of 434 research articles for formal scoring. Once selected for scoring, each full-text article was obtained and classified as either an original research or review article.

Each article was subsequently categorized as emergency care in resource-limited settings (ECRLS), EM development (EMD), or disaster and humanitarian response (DHR). ECRLS includes trauma care, acute medical care, triage, and prehospital care in low- and 
Table 2

Grey Literature Sources

Academic centers/think tanks

1. Global Health Council

2. Center for Global Development

3. The United Nations University

4. RAND Corporation

5. The Woodrow Wilson Center

6. The Bill and Melinda Gates Foundation

7. Center for Global Health Research/University of Toronto

8. Emergency Trauma Care Project

Nongovernmental organizations, United Nations, and government agency websites

1. MEASURE Evaluation

2. MSF

3. Epicentre

4. International Rescue Committee

5. International Medical Corps

6. Oxfam International

7. Oxfam Great Britain

8. GIZ/GTZ

9. International Committee of the Red Cross

10. Centers for Disease Control and Prevention

11. World Health Organization

12. Humanitarian Practice Network

13. UN High Commission for Refugees

14. UN Development Program

15. Inter-Agency Standing Committee

16. UNICEF

17. JHPIEGO

UN $=$ United Nations

middle-income countries or resource-limited settings of high-income countries. EMD includes research on the development of EM as a specialty, EM educational programs, or emergency medical care systems outside of North America, regardless of the national income level. DHR includes research on the care of civilian populations in conflict; disaster mitigation, assessment, and response; and health care of refugees and internally displaced persons.

Each article was then independently scored by two reviewers using a predefined grading scale that assessed for clarity, design, ethics, importance, and impact. Each topical area could be scored from 0 to 5 , totaling a final score range from 0 to 20 (Table 3). The mean of the two scores was used as the final score for the article. Any article with a score difference between reviewers of greater than two standard deviations above the median score difference was rescored by an editor; there were 25 such papers. The editor's score was then used as the final score for the article. Twenty-five articles had final scores of 18 or greater. One of these articles had been authored by a member of our editorial board and was therefore excluded, per our conflict of interest policy. The remaining 24 articles were selected for formal review and were then distributed to reviewers who produced summaries and critiques of each article.

\section{RESULTS}

Of the 434 articles that met our predetermined inclusion criteria, 65\% were categorized as ECRLS, 18\% as EMD, and $17 \%$ as DHR. Approximately $71 \%$ of the articles were original research, while the remaining $29 \%$ were review articles.

Of the 24 articles selected for formal review, 16 (67\%) were categorized as ECRLS, five (21\%) were categorized as EMD, and three (12\%) were categorized as DHR. Twelve articles each were original research manuscripts and review articles, respectively.

The median final score for all articles was 12.5, ranging from 3 to 19.5. There was no significant difference in mean scores between original research (12.4) and review (12.9) articles ( $p=0.233$ ). The differences in mean scores between ECRLS (12.8), EMD (12.4), and DHR (11.6) articles were significant ( $p=0.019)$. Interrater reliability for reviewer scoring, measured using the intraclass correlation coefficient, was $0.630(95 \%$ confidence interval $=0.553$ to 0.693 ), considered "good" reliability in the literature. ${ }^{11,12}$

The top 24 global EM articles for 2013 are listed in Table $4 .{ }^{13-35}$ The complete database of all 434 global EM articles for 2013, as well as full summaries and critical analyses of the top 24 global EM of articles of 2013, can be found in Data Supplements S1 and S2 (available as supporting information in the online version of this article).

\section{DISCUSSION}

Each year, the number of quality articles in the field grows significantly, and thus the mission of the review becomes more challenging. The scope of global EM continues to stretch beyond its initial boundaries to include injury prevention, epidemiologic transition, and knowledge transfer.

Communicable diseases, trauma epidemiology, and prevention, diagnosis, and treatment of diseases common in resource-limited settings dominated the articles selected for final review. After the inclusion of a grey literature article in last year's review, no grey literature article scored above the predefined cutoff for full review in 2013. The number of articles in each of the three categories selected for final review this year remained grossly unchanged when compared to last year. We next summarize some of the 2013 trends in global EM research based on our review.

\section{Emergency Care in Resource-limited Settings}

As in years past, the ECRLS category of articles remains the most represented among articles chosen for full review (67\%). Most of the articles were centered on infectious disease topics.

Gwer et al. ${ }^{21}$ reviewed 14 articles on the clinical management of childhood nontraumatic coma in resourcelimited settings. They found that most cases had infectious etiologies, such as cerebral malaria or meningitis. However, accurate diagnosis and treatment are challenging, particularly when resources are lacking, as often occurs. The authors explore the possibility of using simple tools, such as tympanic membrane displacement for noninvasive monitoring of intracranial pressure and empiric supportive treatment to aid in the clinical management in these settings.

Several studies examined respiratory disease. Moschovis et al. ${ }^{26}$ analyzed data from a large random- 
Table 3

Scoring Criteria

\begin{tabular}{|c|c|c|c|c|}
\hline Criterion & Original Research Article & Points & Review Articles & Points \\
\hline \multirow[t]{4}{*}{ Clarity } & & & Clearly stated purpose for review & 2 \\
\hline & & & Sufficient background provided & 1 \\
\hline & & & Understandable to nonprofessional & 1 \\
\hline & & & $\begin{array}{l}\text { Clear language, appropriate use of tables and } \\
\text { figures }\end{array}$ & 1 \\
\hline \multirow[t]{4}{*}{ Design } & RCT or observational study with control group & 2 & $\begin{array}{l}\text { Formal meta-analysis or systemic review } \\
\text { (including studies with a control group) }\end{array}$ & 2 \\
\hline & $\begin{array}{l}\text { No bias in selection of subjects; attempts to } \\
\text { limit bias }\end{array}$ & 1 & Study selection is clear and reproducible & 1 \\
\hline & Adequate blinding of study subjects & 1 & Article selected by at least two blinded authors & 1 \\
\hline & Correct statistical tests used for analysis & 1 & Data aggregated and/or analyzed appropriately & 1 \\
\hline \multirow[t]{4}{*}{ Ethics } & Approved by IRB & 2 & & \\
\hline & Adheres to Declaration of Helsinki & 1 & & \\
\hline & Consent obtained or waived by IRB & 1 & & \\
\hline & Authors have no $\mathrm{COI}$ & 1 & & \\
\hline \multirow[t]{3}{*}{ Importance } & Results are generalizable to a variety of settings & 2 & $\begin{array}{l}\text { Results are generalizable to a variety of } \\
\text { settings }\end{array}$ & 2 \\
\hline & Topic is important & 2 & Topic is important & 2 \\
\hline & Topic is clearly relevant to GEM & 1 & Topic is clearly relevant to GEM & 1 \\
\hline \multirow[t]{4}{*}{ Impact } & $\begin{array}{l}\text { Recommendations can be implemented in } \\
\text { developing countries }\end{array}$ & 2 & $\begin{array}{l}\text { Recommendations are applicable across a wide } \\
\text { range of different settings }\end{array}$ & 2 \\
\hline & The intervention studied is cost-effective & 1 & The intervention studied is cost-effective & 1 \\
\hline & $\begin{array}{l}\text { NGOs, UN agencies, and other actors would } \\
\text { likely change their practice if they were aware } \\
\text { of this study }\end{array}$ & 1 & $\begin{array}{l}\text { NGOs, UN agencies, and other actors would } \\
\text { likely change their practice if they were aware } \\
\text { of this study }\end{array}$ & 1 \\
\hline & Study results likely to stimulate further research & 1 & Study results likely to stimulate further research & 1 \\
\hline
\end{tabular}

ized control trial (RCT) of 958 children with pneumonia and found that children with baseline anemia are at risk for treatment failure and delayed recovery when at high altitude. A case-control study from Bangladesh demonstrates the high mortality of malnourished children with pneumonia in resource-limited settings and identifies tachypnea and accessory muscle use as the best predictors of hypoxemia, warranting early oxygen supplementation. ${ }^{16}$ Cao et al. ${ }^{15}$ performed a Cochrane Database systematic review of two RCTs on the utility of chest radiographs for the diagnosis of lower respiratory tract infection and found that it offers no benefit when compared to clinical judgment alone. A systematic review and meta-analysis by Breteler et al. ${ }^{14}$ confirms that influenza vaccination in middle-income countries is as effective as in high-income countries.

Diarrheal illnesses continue to be a major cause of morbidity and mortality worldwide; two of the 2013 articles focused on the diagnosis and management of diarrhea. Sarker et al. ${ }^{28}$ performed an RCT of the role of antirotavirus protein in the treatment of rotavirus diarrhea, but its beneficial effects were very limited and of unknown clinical significance. A review article on the emergency management of pediatric diarrhea by Pour et al. $^{36}$ provides a concise summary for practitioners in resource-limited settings. Oral rehydration solution remains the mainstay of treatment in mild to moderate dehydration, while parenteral isotonic crystalloid boluses of 20 to $30 \mathrm{~mL} / \mathrm{kg}$ are advocated for severe dehydration. Where possible, sodium should be monitored during parenteral rehydration. Stool cultures are usually not necessary and do not affect acute man- agement. Antibiotics are not recommended and may be harmful, except in very specific circumstances such as cholera, Shigella, and Clostridium difficile. Zinc supplementation and probiotics are recommended as adjuncts to rehydration, with moderate supporting evidence, while antimotility agents are contraindicated. Postdischarge planning should focus on caregiver instructions on hand hygiene, salty foods and drinks, breastmilk, and return to regular diet, as applicable.

Two studies focused on dengue fever. Gan et al. ${ }^{20}$ performed a retrospective cohort study of more than 1,200 laboratory-confirmed adult cases of dengue and classified their severity based on the 1997 and 2009 WHO criteria. They found that the 2009 criteria were both more sensitive and more specific for the identification of severe cases of dengue. Adherence to the new criteria will therefore likely result in increased necessary hospitalization. A systematic review and meta-analysis of factors associated with dengue shock syndrome by Huy et al. ${ }^{23}$ identified a list of demographic, clinical, and laboratory risk factors.

Another two articles studied malaria. Das et al. ${ }^{17}$ studied whether high-dose or split-dose artesunate improves malaria parasite clearance, a particularly important topic given the rise of partial artemisinin resistance. However, their intervention was not effective, and further research is urgently needed. A doseselection study demonstrates the effectiveness of a new single-dose agent for the prevention of relapses in Plasmodium vivax malaria, but it is not clear whether it is more effective than primaquine. ${ }^{35}$ Based on these results, the substance will be studied further in a phase 
Table 4

Global Emergency Medicine Literature Review 2013 Articles

\begin{tabular}{|c|c|c|c|}
\hline Category & First Author & Title & Journal \\
\hline \multirow{15}{*}{$\begin{array}{l}\text { Emergency } \\
\text { care } \\
\text { in resource- } \\
\text { limited } \\
\text { settings }\end{array}$} & Razzak $^{27}$ & $\begin{array}{l}\text { A child an hour: burden of injury deaths among children under } 5 \text { in } \\
\text { Pakistan }\end{array}$ & Arch Dis Child \\
\hline & Gwer $^{21}$ & $\begin{array}{l}\text { Childhood acute non-traumatic coma: aetiology and challenges in } \\
\text { management in resource-poor countries of Africa and Asia }\end{array}$ & Paediatr Int Child Health \\
\hline & Das $^{17}$ & $\begin{array}{l}\text { Effect of high-dose or split-dose artesunate on parasite clearance in } \\
\text { artemisinin-resistant Falciparum malaria }\end{array}$ & Clin Infect Dis \\
\hline & Kiser $^{24}$ & $\begin{array}{l}\text { Photographic assessment of burn wounds: a simple strategy in a } \\
\text { resource poor setting }\end{array}$ & Burns \\
\hline & Ackaah $^{13}$ & $\begin{array}{l}\text { The use of non-standard motorcycle helmets in low- and middle- } \\
\text { income countries: a multicentre study }\end{array}$ & Inj Prev \\
\hline & $\begin{array}{l}\text { Tubiana } \\
\text { Gan }^{20}\end{array}$ & $\begin{array}{l}\text { Risk factors and predictors of severe leptospirosis in New Caledonia } \\
\text { Implications of discordance in world health organization } 1997 \text { and } \\
2009 \text { dengue classifications in adult dengue }\end{array}$ & $\begin{array}{l}\text { PLoS Negl Trop Dis } \\
\text { PLoS One }\end{array}$ \\
\hline & Chisti $^{16}$ & $\begin{array}{l}\text { Predictors and outcome of hypoxemia in severely malnourished } \\
\text { children under five with pneumonia: a case control design }\end{array}$ & PLoS One \\
\hline & Sarker $^{28}$ & $\begin{array}{l}\text { Anti-rotavirus protein reduces stool output in infants with diarrhea: } \\
\text { a randomized placebo-controlled trial }\end{array}$ & Gastroenterology \\
\hline & $\mathrm{Cao}^{15}$ & Chest radiographs for acute lower respiratory infections & $\begin{array}{l}\text { Cochrane Database } \\
\text { Syst Rev }\end{array}$ \\
\hline & Pour $^{36}$ & Emergency centre care of pediatric diarrhea, an overview & Af J EM \\
\hline & Huy $^{23}$ & $\begin{array}{l}\text { Factors associated with dengue shock syndrome: a systematic } \\
\text { review and meta-analysis }\end{array}$ & PLoS Negl Trop Dis \\
\hline & Miller $^{25}$ & $\begin{array}{l}\text { Causes of puerperal and neonatal sepsis in resource-constrained } \\
\text { settings and advocacy for an integrated community-based postnatal } \\
\text { approach }\end{array}$ & Int J Gynaecol Obstet \\
\hline & $\begin{array}{l}\text { Llanos- } \\
\text { Cuentas }\end{array}$ & $\begin{array}{l}\text { Tafenoquine plus chloroquine for the treatment and relapse } \\
\text { prevention of Plasmodium vivax malaria }\end{array}$ & Lancet \\
\hline & Moschovis $^{26}$ & $\begin{array}{l}\text { Childhood anemia at high altitude: risk factors for poor outcomes in } \\
\text { severe pneumonia }\end{array}$ & Pediatrics \\
\hline & Breteler $^{14}$ & $\begin{array}{l}\text { Efficacy and effectiveness of seasonal and pandemic A (H1N1) } 2009 \\
\text { influenza vaccines in low and middle income countries: a } \\
\text { systematic review and meta-analysis }\end{array}$ & Vaccine \\
\hline \multirow[t]{5}{*}{$\begin{array}{l}\text { EM } \\
\text { development }\end{array}$} & Downie $^{18}$ & $\begin{array}{l}\text { Community-acquired neonatal and infant sepsis in developing } \\
\text { countries: efficacy of WHO's currently recommended antibiotics- } \\
\text { systematic review and meta-analysis }\end{array}$ & Arch Dis Child \\
\hline & $\mathrm{Eze}^{19}$ & $\begin{array}{l}\text { Fatal road traffic injuries in Ibadan, using the mortuary as a data } \\
\text { source }\end{array}$ & Inj Prev \\
\hline & Senarathna ${ }^{29}$ & $\begin{array}{l}\text { Effect of a brief outreach educational intervention on the translation } \\
\text { of acute poisoning treatment guidelines to practice in rural } \\
\text { Sri Lankan hospitals: a cluster randomized trial }\end{array}$ & PLoS One \\
\hline & Wilson ${ }^{34}$ & $\begin{array}{l}\text { A systematic review and thematic synthesis of qualitative studies } \\
\text { on maternal emergency transport in low- and middle-income } \\
\text { countries }\end{array}$ & Int J Gynaecol Obstet \\
\hline & Wesson $^{33}$ & $\begin{array}{l}\text { The cost of injury and trauma care in low- and middle-income } \\
\text { countries: a review of economic evidence }\end{array}$ & Health Policy Plan \\
\hline \multirow[t]{3}{*}{$\begin{array}{l}\text { Disaster and } \\
\text { humanitarian } \\
\text { response }\end{array}$} & Spangaro ${ }^{30}$ & $\begin{array}{l}\text { What evidence exists for initiatives to reduce risk and incidence of } \\
\text { sexual violence in armed conflict and other humanitarian crises? } \\
\text { A systematic review }\end{array}$ & PLoS One \\
\hline & $\mathrm{Hill}^{22}$ & $\begin{array}{l}\text { Desa SIAGA', the 'Alert Village': the evolution of an iconic brand in } \\
\text { Indonesian public health strategies }\end{array}$ & Health Policy Plan \\
\hline & Tempark $^{31}$ & Flood-related skin diseases: a literature review & Int J Dermatol \\
\hline
\end{tabular}

III trial. Miller et al. ${ }^{25}$ identified culprit microorganisms causing puerperal and neonatal sepsis in low-income countries. These data can help to improve empiric treatment protocols.

The final infectious disease topic covered in this year's review is leptospirosis. Tubiana et al. ${ }^{32}$ identified three risk factors and five prognostic factors for the development of severe or fatal disease, using a retrospective study design. Clinicians may use this information to identify at-risk patients.

Injury is now exceeding communicable illnesses as a leading cause of death in many countries. ${ }^{37}$ A study from Pakistan, titled "A Child An Hour," surveyed over
95,000 households. ${ }^{27}$ They found that injury mortality for children less than 5 years of age is five times greater than in high-income countries. Based on their data, the authors make several recommendations for injury prevention.

Two studies examined specific causes of injury: burns and motorcycle accidents. Burns remain a common cause of injury in resource-limited settings, yet expert consultation is often not available. Kiser et al. ${ }^{24}$ found that photographic burn wound assessment may be a feasible option for remote expert consultation. Ackaah et al. ${ }^{13}$ published a multicountry analysis of nonstandard motorcycle helmet use (i.e., use of noncertified or 
damaged helmets or use of helmets designed for other purposes) in resource-limited settings. They found that nonstandard helmet use is widespread, and their use is most significantly associated with their lower cost. These findings demonstrate that while helmet use may be growing, the public health safety dividends may not pay off if motorcycle riders are using potentially hazardous helmets.

\section{Emergency Medicine Development}

This year $21 \%$ of the articles selected for full review were from the EMD category, with a focus on maternal and child health, as well as injury. Wilson et al. ${ }^{34}$ performed a systematic review of barriers to the utilization of transport for emergency obstetric care, information that can help policy-makers improve access to this kind of care in resource-limited settings. Downie et al. ${ }^{18}$ compared current WHO recommendations for the treatment of neonatal and infant sepsis and their efficacy in community settings in their systematic review and meta-analysis. They found high rates of resistance to the recommended first-line antibiotics. Most of the evidence supporting the WHO recommendations has been derived from tertiary hospital data, and this study supports a reevaluation of the current antibiotic recommendations for community-dwelling patients. Finally, a study from Sri Lanka demonstrated that a brief educational workshop increased adherence to emergency treatment guidelines for acute poisonings, when compared to distributing printed guidelines alone. ${ }^{29}$

Wesson et al. ${ }^{33}$ systematically reviewed the literature on the economic cost of injury and the cost-effectiveness of injury prevention measures in low- and middle-income countries. They identified several lowcost preventative interventions that could help inform policy-makers in these countries to improve trauma care systems and injury prevention. A study from Nigeria demonstrates that detailed fatality data on road traffic injuries can be collected via mortuary-based surveillance. ${ }^{19}$ This approach can identify previously unreported road traffic fatalities, thus allowing a more accurate distribution of trauma system resources.

\section{Disaster and Humanitarian Response}

In 2013, articles from this category comprised $12.5 \%$ of the fully reviewed articles. One review article reported on the prevalence of skin diseases after flooding and found that the majority of these are inflammatory in etiology. ${ }^{31}$ Spangaro et al. ${ }^{30}$ performed a systematic review to survey initiatives to reduce sexual violence in humanitarian crises in limited resource settings. Despite the extensive literature on sexual violence by military combatants, the vast majority of the interventions addressed opportunistic forms of sexual violence committed in postconflict settings. The third study demonstrates that a locally derived obstetric care program successfully used branding to transform into a national

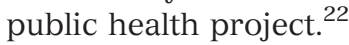

\section{CONCLUSIONS}

Global emergency medicine is a field that is quickly growing in both depth and breadth. As the specialty expands, the body of literature it produces continues to increase and diversify. These articles represent examples of both high-quality and high-impact emergency medicine research currently being conducted around the world. The Global Emergency Medicine Literature Review does not produce an exhaustive list of articles. Rather, it highlights an important sample of the current literature. We hope these articles will foster further growth in the field, promote evidence-based practice, and encourage global discourse and further research.

\section{References}

1. Jacquet GA, Foran M, Bartels S, et al. Global emergency medicine: a review of the literature from 2012. Acad Emerg Med 2013;20:835-43.

2. Schroeder ED, Jacquet G, Becker TK, et al. Global emergency medicine: a review of the literature from 2011. Acad Emerg Med 2012;19:1196-203.

3. Aschkenasy M, Arnold K, Foran M, et al. International emergency medicine: a review of the literature from 2010. Acad Emerg Med 2011;18:872-9.

4. Foran M, Levine A, Lippert S, et al. International emergency medicine: a review of the literature from 2009. Acad Emerg Med 2011;18:86-92.

5. Levine AC, Becker J, Lippert S, Rosborough S, Arnold K. International emergency medicine: a review of the literature from 2007. Acad Emerg Med 2008; 15:860-5.

6. Levine AC, Gadiraju S, Goel A, Johar S, King R, Arnold K. International emergency medicine: a review of the literature. Acad Emerg Med 2007;14:182-3.

7. Levine AC, Goel A, Keay CR, et al. International emergency medicine: a review of the literature from 2006. Acad Emerg Med 2007;14:1190-3.

8. Lippert S, Levine AC, Becker J, Foran M, Rosborough S, Arnold K. International emergency medicine: a review of the literature from 2008. Acad Emerg Med 2009;16:1335-40.

9. GreyNet International. Grey Literature Network Service. Available at: http://www.greynet.org/greynethome/aboutgreynet.html. Accessed Apr 24, 2014.

10. GEMLR Procedures Manual 2013. Available at: http://www.gemlr.org/uploads/1/4/6/4/14642448/2012_ gemlr_procedures_manual_abridged.doc. Accessed Apr 24. 2014.

11. Shrout PE, Fleiss JL. Intraclass correlations: uses in assessing rater reliability. Psychol Bull 1979;86:4208.

12. Cicchetti DV, Sparrow SA. Developing criteria for establishing interrater reliability of specific items: applications to assessment of adaptive behavior. Am J Ment Defic 1981;86:127-37.

13. Ackaah W, Afukaar F, Agyemang W, et al. The use of non-standard motorcycle helmets in low- and middle-income countries: a multicentre study. Inj Prev 2013;19:158-63.

14. Breteler JK, Tam JS, Jit M, Ket JC, De Boer MR. Efficacy and effectiveness of seasonal and pandemic A (H1N1) 2009 influenza vaccines in low and middle income countries: a systematic review and metaanalysis. Vaccine 2013;31:5168-77. 
15. Cao AM, Choy JP, Mohanakrishnan LN, Bain RF, van Driel ML. Chest radiographs for acute lower respiratory tract infections. Cochrane Database Syst Rev 2013;12:CD009119.

16. Chisti MJ, Salam MA, Ashraf H, et al. Predictors and outcome of hypoxemia in severely malnourished children under five with pneumonia: a case control design. PLoS One 2013;8:e51376.

17. Das D, Tripura R, Phyo AP, et al. Effect of high-dose or split-dose artesunate on parasite clearance in artemisinin-resistant falciparum malaria. Clin Infect Dis 2013;56:e48-58.

18. Downie L, Armiento R, Subhi R, Kelly J, Clifford V, Duke T. Community-acquired neonatal and infant sepsis in developing countries: efficacy of WHO's currently recommended antibiotics-systematic review and meta-analysis. Arch Dis Child 2013;98:146-54.

19. Eze UO, Kipsaina CC, Ozanne-Smith J. Fatal road traffic injuries in Ibadan, using the mortuary as a data source. Inj Prev 2013;19:387-92.

20. Gan VC, Lye DC, Thein TL, Dimatatac F, Tan AS, Leo YS. Implications of discordance in World Health Organization 1997 and 2009 dengue classifications in adult dengue. PLoS One 2013;8:e60946.

21. Gwer S, Chacha C, Newton CR, Idro R. Childhood acute non-traumatic coma: aetiology and challenges in management in resource-poor countries of Africa and Asia. Paediatr Int Child Health 2013;33:129-38.

22. Hill PS, Goeman L, Sofiarini R, Djara MM. 'Desa SIAGA', the 'Alert Village': the evolution of an iconic brand in Indonesian public health strategies. Health Policy Plan 2013:DOI 10.1093/heapol/czt027

23. Huy NT, Van Giang T, Thuy DH, et al. Factors associated with dengue shock syndrome: a systematic review and meta-analysis. PLoS Negl Trop Dis 2013; 7:e2412.

24. Kiser M, Beijer G, Mjuweni S, Muyco A, Cairns B, Charles A. Photographic assessment of burn wounds: a simple strategy in a resource-poor setting. Burns 2013;39:155-61.

25. Miller AE, Morgan C, Vyankandondera J. Causes of puerperal and neonatal sepsis in resource-constrained settings and advocacy for an integrated community-based postnatal approach. Int J Gynaecol Obstet 2013;123:10-5.

26. Moschovis PP, Banajeh S, MacLeod WB, et al. Childhood anemia at high altitude: risk factors for poor outcomes in severe pneumonia. Pediatrics 2013;132:e1156-62.

27. Razzak JA, Khan UR, Zia N, Azam I. A child an hour: burden of injury deaths among children under 5 in Pakistan. Arch Dis Child 2013;98:867-71.

28. Sarker SA, Jakel M, Sultana S, et al. Anti-rotavirus protein reduces stool output in infants with diarrhea: a randomized placebo-controlled trial. Gastroenterology 2013;145:740-8.

29. Senarathna L, Buckley NA, Dibley MJ, et al. Effect of a brief outreach educational intervention on the translation of acute poisoning treatment guidelines to practice in rural Sri Lankan hospitals: a cluster randomized controlled trial. PLoS One 2013;8: e71787.

30. Spangaro J, Adogu C, Ranmuthugala G, Powell Davies G, Steinacker L, Zwi A. What evidence exists for initiatives to reduce risk and incidence of sexual violence in armed conflict and other humanitarian crises? A systematic review. PLoS One 2013;8: e62600.

31. Tempark T, Lueangarun S, Chatproedprai S, Wananukul S. Flood-related skin diseases: a literature review. Int J Dermatol 2013;52:1168-76.

32. Tubiana S, Mikulski M, Becam J, et al. Risk factors and predictors of severe leptospirosis in New Caledonia. PLoS Negl Trop Dis 2013;7:e1991.

33. Wesson HK, Boikhutso N, Bachani AM, Hofman KJ, Hyder AA. The cost of injury and trauma care in low- and middle-income countries: a review of economic evidence. Health Policy Plan 2013:DOI 10. 1093/heapol/czt064

34. Wilson A, Hillman S, Rosato M, et al. A systematic review and thematic synthesis of qualitative studies on maternal emergency transport in low- and middle-income countries. Int $\mathrm{J}$ Gynaecol Obstet 2013;122:192-201.

35. Llanos-Cuentas A, Lacerda MV, Rueangweerayut R, et al. Tafenoquine plus chloroquine for the treatment and relapse prevention of Plasmodium vivax malaria (DETECTIVE): a multicentre, double-blind, randomised, phase $2 \mathrm{~b}$ dose-selection study. Lancet 2014;383:1049-58.

36. Pour RT, Koyfman A, Runyon MS. Emergency centre management of paediatric diarrhoea: an overview. Af J Emerg Med 2013;3:75-82.

37. Mathers CD, Boerma T, Ma Fat D. Global and regional causes of death. Br Med Bull 2009;92:7-32.

\section{Supporting Information}

The following supporting information is available in the online version of this paper:

Data Supplement S1. GEMLR reviews of articles included for full review in 2013.

Data Supplement S2. GEMLR 2013 database of all 434 articles included for formal scoring.

\section{APPENDIX A}

Global Emergency Medicine Literature Review (GEMLR) Group (alphabetical)

Nada A-Rahman, MD, MBBS, Department of Internal Medicine, University of Bahri, Khartoum, and Omdurman Accident \& Emergency Hospital, Omdurman, Sudan

Kris Arnold, MD, MPH, ArLac Health Services, Boston, MA

Miriam Aschkenasy, MD, MPH, Center for Global Health at Massachusetts General Hospital, Boston, MA, and Harvard Humanitarian Initiative, Cambridge, MA

Kamna S. Balhara, MD, MA, Department of Emergency Medicine, John Hopkins University, Baltimore, MD 
Susan Bartels, MD, MPH, Department of Emergency Medicine, Beth Israel Deaconess Medical Center, Boston, MA; FXB Center for Health and Human Rights, Boston, MA; and Harvard Humanitarian Initiative, Cambridge, MA

Torben K. Becker, MD, Department of Emergency Medicine, University of Michigan, Ann Arbor, MI

Mark Bisanzo, MD, DTM\&H, Department of Emergency Medicine, University of Massachusetts, Worcester, MA

Aislinn Black, DO, Department of Emergency Medicine, SUNY at Stony Brook, Stony Brook, NY

Michael Boyd, MD, Department of Emergency Medicine, University of Michigan, Ann Arbor, MI

Jennifer Chan, MD, MPH, Department of Emergency Medicine, Northwestern Memorial Hospital, Chicago, IL, and Harvard Humanitarian Initiative, Cambridge, MA

Samah Chiry, MD, MSc, Department of Family/Emergency Medicine, McGill University, Montréal, QC, Canada

Hannah Cockrell, Department of Emergency Medicine, Rhode Island Hospital, Providence, RI

Herbert C. Duber, MD, MPH, Division of Emergency Medicine, University of Washington, Seattle, WA

Mark Foran, MD, MPH, Department of Emergency Medicine, New York University, New York, NY, and Harvard Humanitarian Initiative, Cambridge, MA

Bhakti Hansoti, MBChB, Department of Emergency Medicine, Johns Hopkins University, Baltimore, MD

Alison S. Hayward, MD, MPH, Yale School of Medicine, New Haven, CT

Braden Hexom, MD, Department of Emergency Medicine, Icahn School of Medicine at Mount Sinai, New York, NY

Gabrielle A. Jacquet, MD, MPH, Department of Emergency Medicine, Boston University School of Medicine, and Boston University Center for Global Health and Development, Boston, MA

Joshua Jauregui, MD, Division of Emergency Medicine, University of Washington, Seattle, WA

Andrew Kestler, MD, MBA, DTMH, Department of Emergency Medicine, University of British Columbia and St. Paul's Hospital, Vancouver, BC, Canada

Okechukwu Ogbonna Jibuike, MBBS, FRCS, PG Dip Healthcare, MCEM, MACEM, MSEM, MFMLM, Trafford General Hospital Manchester, Division of Central Manchester University Hospital NHS Foundation Trust, Manchester, United Kingdom
Maxwell Osei-Ampofo, MBChB, MBA, MGCS(EM), Accident \& Emergency Department, Komfo Anokye Teaching Hospital and Kwame Nkrumah University of Science and Technology, Kumasi, Ghana

Stephanie Kayden, MD, MPH, Department of Emergency Medicine, Brigham and Women's Hospital, Boston, MA, and Harvard Humanitarian Initiative, Cambridge, MA

Adam C. Levine, MD, MPH, Department of Emergency Medicine, Rhode Island Hospital, Providence RI, and Harvard Humanitarian Initiative, Cambridge, MA

Xiaoguang Li, MD, Shanghai United Family Hospital, Shanghai, China

Kevin Lunney, MD, PhD, Medical Corps, US Navy, Department of Emergency Medicine, Navy Hospital Camp Lejeune, Camp Lejeune, NC

Regan H. Marsh, MD, MPH, Department of Emergency Medicine, Brigham and Women's Hospital, Boston, MA, and Partners In Health, Boston, MA

Dan Millikan, MD, Department of Emergency Medicine, Providence Regional Medical Center, Everett, WA

Payal Modi, MD, MPH, Department of Emergency Medicine, Brigham and Women's Hospital, Boston, MA, and Harvard Humanitarian Initiative, Cambridge, MA

Terrence Mulligan, DO, MPH, Department of Emergency Medicine, University of Maryland School of Medicine, Baltimore, MD

Usha Periyanayagam, MD, MPH, MS, Department of Emergency Medicine, Northwestern Memorial Hospital, Chicago, IL

Michael Runyon, MD, Department of Emergency Medicine, Carolinas Medical Center, Charlotte, NC

Erika D. Schroeder, MD, MPH, Department of Emergency Medicine, George Washington University, Washington, DC, and Department of Emergency Medicine, Providence Regional Medical Center, Everett, WA

Nagi Souaiby, MD, MPH, MHM, Department of Emergency Medicine, Faculty of Medicine, St. Joseph University, Beirut, Lebanon

Indi Trehan, MD, MPH, DTM\&H, Department of Pediatrics,Washington University, St. Louis, MO

Benjamin W. Wachira, Dip PEC (SA), MMed (EM), FCEM (SA), Accident \& Emergency Department, Aga Khan University Hospital, Nairobi, Kenya

Ambrose H. Wong, MD, Department of Emergency Medicine, New York University, New York, NY

Wah Hon Yau, MBBS, FHKAM (EM), FHKCEM, MRCS (Ed), Hong Kong Sanatorium and Hospital, Hong Kong, China 